Document downloaded from:

http://hdl.handle.net/10251/47366

This paper must be cited as:

Robles Martínez, A.; Ruano García, MV.; Ribes Bertomeu, J.; Ferrer, J. (2012). Sub-critical long-term operation of industrial scale hollow-fibre membranes in a submerged anaerobic MBR (HF-SAnMBR) system. Separation and Purification Technology. 100:88-96. doi:10.1016/j.seppur.2012.09.010.

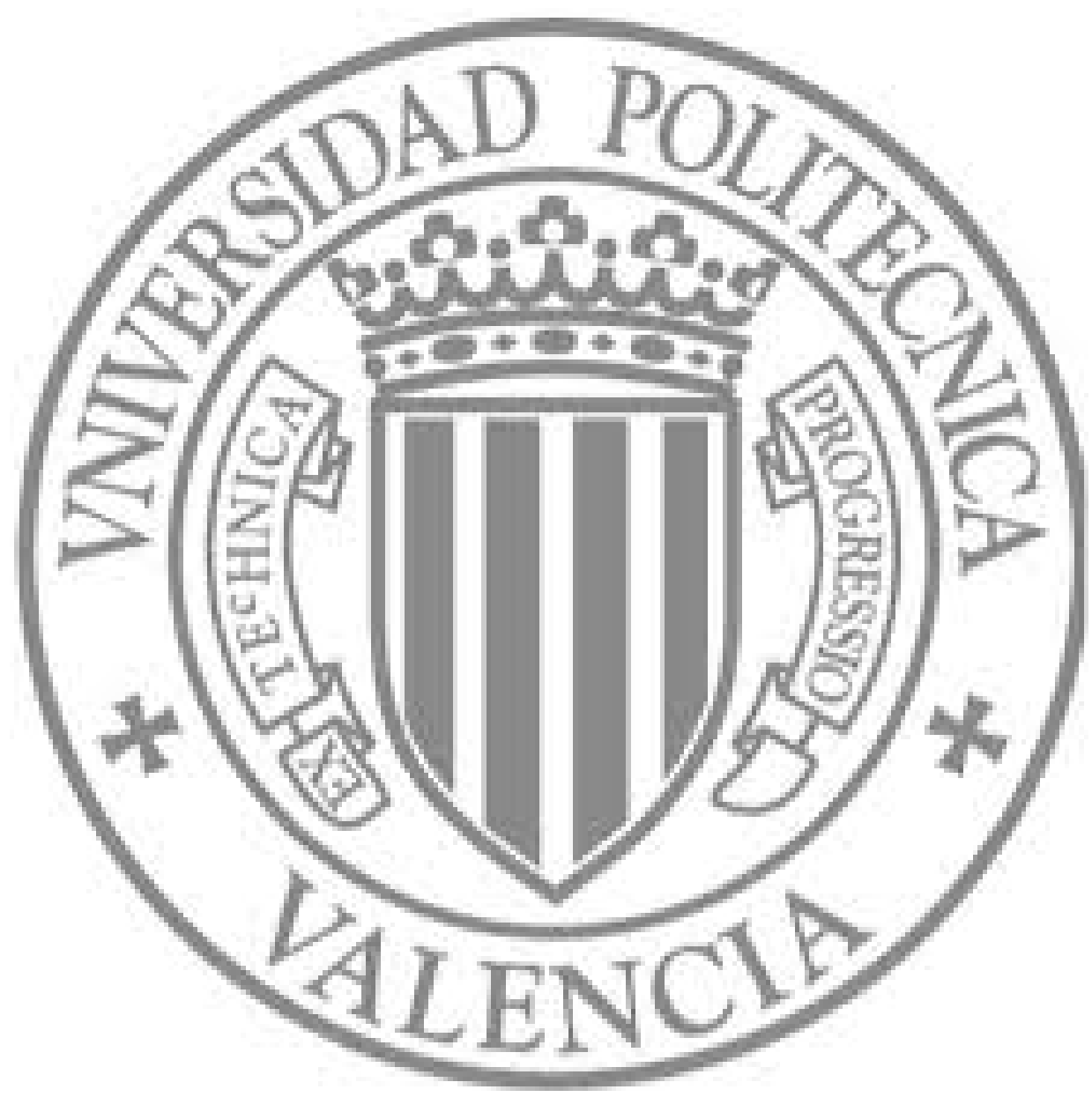

The final publication is available at

http://dx.doi.org/10.1016/j.seppur.2012.09.010

Copyright Elsevier 


\title{
Sub-critical long-term operation of industrial scale hollow-fibre membranes in a submerged anaerobic MBR (HF-SAnMBR) system
}

\author{
A. Robles ${ }^{\mathrm{a}, *}$, M.V. Ruano ${ }^{\mathrm{b}}$, J. Ribes $^{\mathrm{b}}$ and J. Ferrer ${ }^{\mathrm{a}}$ \\ a Institut Universitari d'Investigació d'Enginyeria de l'Aigua i Medi Ambient, IIAMA, \\ Universitat Politècnica de València, Camí de Vera s/n, 46022, Valencia, Spain (e-mail: \\ ngerobma@upv.es; jferrer@hma.upv.es)

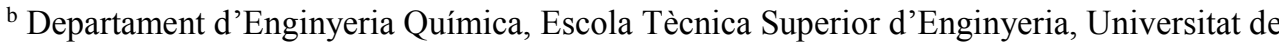 \\ València, Avinguda de la Universitat s/n, 46100, Burjassot, Valencia, Spain (e-mail: \\ m.victoria.ruano@uv.es; josep.ribes@uv.es) \\ * Corresponding author: tel. +34 9638799 61, fax +34 9638790 09, e-mail: \\ ngerobma@upv.es
}

\begin{abstract}
The aim of this study was to evaluate the long-term performance of hollow-fibre (HF) membranes used to treat urban wastewater in a Submerged Anaerobic MBR when operating sub-critically. To this end, a demonstration plant with two industrial scale HF ultrafiltration membrane modules was operated under different conditions. The main factor affecting membrane performance was the concentration of mixed liquor total solids (MLTS). The reversible fouling rate remained low even when MLTS levels (about $25 \mathrm{~g} \mathrm{~L}^{-1}$ ) in the membrane tank were high. No chemical cleaning was conducted whilst operating the plant for more than one year because no irreversible fouling problems were detected. The almost complete absence of irreversible fouling was mainly attributed to: operating at sub-critical filtration conditions; establishing a proper membrane operating mode; and to the characteristics of the anaerobic environment. No chemical precipitation problems were observed in the membranes due to the relatively low operating $\mathrm{pH}$ (always below 7) of the sludge. The biogas sparging encouraged high levels of dissolved $\mathrm{CO}_{2}$ in the sludge, resulting in $\mathrm{pH}$ levels below 7 and alkalinity values around 600
\end{abstract}


$m g \mathrm{CaCO}_{3} \mathrm{~L}^{-1}$.

\section{Keywords}

Filtering resistance; industrial scale hollow-fibre membranes; long-term operation; sub-critical filtration; submerged anaerobic MBR.

\section{Introduction}

Because of an increased interest in sustainability within wastewater management, there has been growing attention in recent years in the study of anaerobic urban wastewater treatment at ambient temperatures. Interest has focused on the greater sustainability advantages of anaerobic processes over aerobic processes, i.e. low sludge production due to low anaerobic biomass yield; low energy consumption because no aeration is required; the production of biogas that can be used as energy; and low greenhouse gases emissions when methane is recovered from both biogas and effluent streams. The main challenge posed by anaerobic biotechnology is how to develop treatment systems that prevent biomass loss whilst enabling high sludge retention times (SRTs) in order to compensate for the low growth rates of anaerobic biomass at ambient temperatures [1]. Against the well-established Up-flow Anaerobic Sludge Blanket (UASB) and Expanded Granular Sludge Blanket (EGSB) reactor configurations, anaerobic membrane bioreactors (AnMBRs) allow meeting longer SRTs, which is the main requirement necessary for high-rate anaerobic treatment. These longer SRTs are possible since complete physical retention of solids and almost all microorganisms can be achieved in membrane separation processes. Hence, AnMBRs provide an alternative strategy for urban wastewater treatment at ambient temperatures with the potential for a high quality effluent [2]. 
However, operating membrane bioreactors with long SRTs commonly means working with high MLTS levels, which is precisely one of the main operating drawbacks of membranes [3]. These high MLTS levels contribute to membrane fouling: the key issue of membrane technology. Membrane fouling decreases membrane permeability $(\mathrm{K})$ and increases operating and maintenance costs [4]. Therefore, the need to work with high SRTs during the anaerobic treatment of low strength wastewaters could lead to high MLTS levels, in which case higher reactor volume might be required in order to operate at lower MLTS levels. In this respect, in order to design this technology adequately, the effect of MLTS on membrane fouling must be assessed.

In addition to MLTS level, other sludge properties have been identified elsewhere as key factors affecting membrane performance [5], such as $\mathrm{pH}$ and chemical precipitation. For instance, aerobic MBRs usually have high $\mathrm{pH}$ values probably because of the considerable $\mathrm{CO}_{2}$ stripped from the liquid phase by the air sparging used in both membrane scouring and aeration. In this respect, the solubility of chemical precipitates is directly related to the $\mathrm{pH}$ when a representative amount of salts is present in the mixed liquor. For instance, Martí et al. [6] found that the amount of fixed phosphorous (mainly in the form of struvite) increases at $\mathrm{pH}$ values above 7.1.

In order to minimise any kind of membrane fouling (reversible, irreversible, or irrecoverable) and thereby increase membrane life span, the main operating challenge for AnMBRs is to optimise membrane operation and configuration. Several fouling control strategies can be applied [7, 8,9], which must be able to optimise the filtration process with minimum operating and investment cost. The main points of these control strategies as regards membrane operation are: optimising the frequency and duration of the physical cleaning stages (back-flush and relaxation); optimising different operating 
variables such as gas sparging intensity or permeate/influent flow rate ratios; and operating membranes under the sub-critical filtration conditions bounded by critical flux $\left(\mathrm{J}_{\mathrm{C}}\right)[10,11]$. As for membrane configuration, hollow fibre (HF) membranes are used for the entire flow range and account for about $75 \%$ of all total MBR installed capacity [12]. HF membranes require little energy due mainly to the low transmembrane pressure (TMP) required for filtration. Moreover, HF membranes are situated in the mixed liquor itself (out-in filtration) and some of the biogas produced can be recycled to the bottom of the membrane tank for in-situ sparging [1].

Therefore, the key challenge in AnMBR technology is how to achieve suitable long-term membrane performances at competitive transmembrane fluxes ( $\mathrm{J}$ ) whilst reducing membrane fouling propensity. Martinez-Sosa et al. [13] achieved considerable low fouling rates at $\mathrm{J}$ of $7 \mathrm{LMH}$ when operating under psychrophilic temperature conditions in a range of total suspended solids (TSS) from approx. 9.5 to $17.5 \mathrm{~g} \mathrm{~L}^{-1}$. However, stable membrane operation was achieved neither at 12 nor at $10 \mathrm{LMH}$ and TSS of around $13-14 \mathrm{~g} \mathrm{~L}^{-1}$. Under mesophilic temperature conditions, Martinez-Sosa et al. [14] reported a stable membrane operation at J of 7 LMH and TSS from approx. 15 to $20 \mathrm{~g} \mathrm{~L}^{-1}$. Nevertheless, under psychrophilic temperature conditions, considerable high fouling rates were observed operating at $7 \mathrm{LMH}$ when TSS was over $17 \mathrm{~g} \mathrm{~L}^{-1}$. Akram et al. [15] operated at J of 10 LMH resulting in low TMP values around 0.1 bars, whilst Yoo et al. [16] achieved stable long-term membrane operation (TMP values generally lower than 0.1 bars) at J of up to $11-12 \mathrm{LMH}$. However, these higher $\mathrm{J}$ values were possible because of the scouring effect on membrane surface of the fluidised activated carbon introduced to the system. 
Several studies have been published about the feasibility of submerged anaerobic MBRs (SAnMBRs) for treating urban wastewater on a laboratory scale [17, 18, 19, 20, 21], but few about the use of SAnMBR technology with commercial membranes on an industrial scale. Moreover, the impact of the main operating conditions on membrane fouling has not been adequately evaluated on the lab scale because it depends to a large extent on the membrane size. In HF membranes in particular, the HF length is a key design parameter, which means that they cannot be directly scaled up from the laboratory scale to full scale. Therefore, further studies are needed on HF membranes at the industrial scale in order to facilitate the design and implementation of SAnMBR technology in full-scale WWTPs.

In order to shed more light on the optimisation of the physical separation process in SAnMBRs systems on an industrial scale, this paper now analyses the long-term performance of commercial HF membranes. In order to obtain accurate results that could be extrapolated to the design and operation of full-scale plants, an SAnMBR system featuring industrial scale HF membrane modules was operated with effluent from the pre-treatment of the Carraixet WWTP (Valencia, Spain). Several parameters that affect the physical separation process in SAnMBR technology were studied, i.e. 20 ${ }^{\circ} \mathrm{C}$-normalised transmembrane flux $\left(\mathrm{J}_{20}\right)$, MLTS level, $\mathrm{pH}$, carbonate alkalinity (Alk) and chemical precipitation propensity. The novelty of this study lies in analysing the feasibility of the physical separation process featured in this technology under specific conditions that are similar to the ones expected at full-scale plants.

\section{Materials and methods}

\subsection{Demonstration plant description}


Figure 1 shows the flow diagram of the HF-SAnMBR demonstration plant used in this study. It consists of an anaerobic reactor with a total volume of $1.3 \mathrm{~m}^{3}\left(0.4 \mathrm{~m}^{3}\right.$ headspace biogas volume) connected to two membrane tanks each with a total volume of 0.8 $\mathrm{m}^{3}\left(0.2 \mathrm{~m}^{3}\right.$ head-space biogas volume $)$. Each membrane tank has one industrial scale ultrafiltration membrane unit $\left(\mathrm{PURON}^{\circledR}\right.$, Koch Membrane Systems (PUR-PSH31) with $0.05 \mu \mathrm{m}$ pores). The membrane unit consists of braided HF membranes (polyethersulfone (PES)) for outside-in operation. Each module has 9 HF bundles, 1.8 $\mathrm{m}$ long, giving a total membrane surface of $30 \mathrm{~m}^{2}$. Moreover, each tank allows recycling continuously the obtained permeate to the anaerobic reactor. The obtained permeate from MT1 (see Figure 1) was continuously recycled to the system in order to test different $\mathbf{J}_{20}$ without affecting the hydraulic retention time (HRT) of the process. On the other hand, the biological process was operated by using MT2 (see Figure 1), which worked without recycling the obtained permeate. The biological process was operated at different HRTs tested by means of setting different operating filtration modes in MT2. As a result the MLTS level in the anaerobic sludge varied throughout the experimental period. In this work, the filtration process results that are presented correspond to the experimental data obtained from MT1.

Normal membrane operating entails a specific schedule involving a combination of different individual stages taken from a basic filtration-relaxation (F-R) cycle. In addition to traditional membrane operating stages (filtration, relaxation and back-flush), another two stages of membrane operation were considered: degasification and ventilation [22].

Numerous on-line sensors and automatic devices were installed in order to 
automate and control the plant operation and provide on-line information about the state of the process. In particular a group of on-line sensors was assigned to each membrane tank consisting of: $1 \mathrm{pH}$-temperature transmitter; 1 level indicator transmitter; 1 flow indicator transmitter for the mixed liquor feed pump; 1 flow indicator transmitter for the permeate pump; and 1 liquid pressure indicator transmitter in order to control the TMP. The group of actuators assigned to each membrane tank consisted of a group of on/off control valves that determine the direction of the flow in order to control the different membrane operating stages (filtration, back-flush, relaxation...) plus 3 frequency converters. Each frequency converter controls the rotating speed of the permeate pump, the mixed liquor feed pump, and the membrane tank blower. Further details about this SAnMBR demonstration plant can be found in Robles et al. [22].

\subsection{Demonstration plant operation}

The demonstration plant was operated at an SRT of 70 days. During the experimental period of our study, the usual membrane operating mode was as follows: a 300 -second basic F-R cycle (250 s filtration and 50 s relaxation), 30 seconds of backflush every 10 F-R cycles, 40 seconds of ventilation every 10 F-R cycles, and 30 seconds of degasification every 50 F-R cycles. Four gross $\mathbf{J}_{20}$ were tested in this work: 13.3, 10, 12 and 13.3 $\mathrm{LMH}$, at controlled temperatures of $33,33,25$, and $20^{\circ} \mathrm{C}$, respectively. Hence, the operating period was divided in four experimental periods (Period i, ii, iii and iv) taking into account both $\mathrm{J}_{20}(13.3,10,12$, and $13.3 \mathrm{LMH}$, respectively) and temperature $\left(33,33,25\right.$ and $20^{\circ} \mathrm{C}$, respectively). The long-term operation was carried out under sub-critical filtration conditions. To this end, the average specific gas demand per membrane area ( $\mathrm{SGD}_{\mathrm{m}}$ ) was set to $0.23 \mathrm{Nm}^{3} \mathrm{~h}^{-1} \mathrm{~m}^{-2}$, taking into account the expected MLTS level. The maximum security value for the TMP 
was set to 0.4 bars. The cross-flow sludge velocity over the membrane surface was set to $2.7 \mathrm{~mm} \mathrm{~s}^{-1}$.

Important to highlight is the wide variation in the anaerobic reactor influent loads during the experimental period (e.g. $186 \pm 61 \mathrm{mg} \mathrm{L}^{-1}$ of TSS or $388 \pm 95 \mathrm{mg} \mathrm{L}^{-1}$ of COD), reflected by the high standard deviation of each parameter. The uncertainty associated with each value includes both the standard deviation of the different samples analysed throughout the experiment and the variation coefficient associated with the analytical methods. The plant was fed with effluent from pre-treatment of a full-scale WWTP (screening, degritter, and grease removal), which main component is domestic type. No significant levels of process inhibitors were detected (i.e. oil, grease, heavy metals, conductivity, etc.).

\subsection{Analytical methods}

\subsubsection{Analytical monitoring}

In addition to monitoring the process on-line, the performance of the biological process was assessed by taking 24-hour composite samples from influent and effluent streams, and taking grab samples of biogas and anaerobic sludge once a day. The following parameters were analysed: total solids (TS); TSS; COD; carbonate alkalinity (Alk); sulphate $\left(\mathrm{SO}_{4}-\mathrm{S}\right)$; sulphide $\left(\mathrm{HS}^{-}\right)$; nitrite $\left(\mathrm{NO}_{2}-\mathrm{N}\right)$ and nitrate $\left(\mathrm{NO}_{3}-\mathrm{N}\right)$; and nutrients (ammonium $\left(\mathrm{NH}_{4}-\mathrm{N}\right)$ and orthophosphate $\left(\mathrm{PO}_{4}-\mathrm{P}\right)$ ). In addition, the following ion concentrations were analysed: chlorine $\left(\mathrm{Cl}^{-}\right)$; magnesium $\left(\mathrm{Mg}^{2+}\right)$; calcium $\left(\mathrm{Ca}^{2+}\right)$; potassium $\left(\mathrm{K}^{+}\right)$; and sodium $\left(\mathrm{Na}^{+}\right)$. 
Solids, COD, sulphate, sulphide, nitrite and nitrate, nutrients, and ions were determined according to Standard Methods [23]. Carbonate alkalinity was determined by titration according to the method proposed by WRC [24].

\subsubsection{Membrane performance indices}

A classical resistance model (Eq. 1) was used in order to quantify the total membrane resistance $\left(\mathrm{R}_{\mathrm{T}}\right)$, which was theoretically represented by the following partial resistances: membrane resistance $\left(\mathrm{R}_{\mathrm{M}}\right)$; cake layer resistance $\left(\mathrm{R}_{\mathrm{C}}\right)$; and irreversible layer resistance $\left(\mathrm{R}_{\mathrm{I}}\right) . \mathrm{J}_{\mathrm{T}}$ was corrected (Eq. 2) to $20^{\circ} \mathrm{C}\left(\mathrm{J}_{20}\right)$ to account for the dependence of permeate viscosity $(\mu)$ on temperature $(T)$. The fouling rate was calculated using a classical regression model (Eq. 3) that takes into account the total number of data monitored (n) during the filtration time $(\mathrm{t})$ in order to minimise any possible noise from the pressure indicator transmitter.

$$
\begin{aligned}
& R_{T}=R_{M}+R_{C}+R_{I}=\frac{T M P}{\mu \cdot J_{T}} \\
& J_{20}=J_{T} \cdot e^{-0.0239(T-20)} \\
& \frac{\partial T M P}{\partial t}=\frac{n \cdot \sum_{1}^{n}\left(T M P_{i} \cdot t_{i}\right)+\sum_{1}^{n} T M P_{i} \cdot \sum_{1}^{n} t_{i}}{n \cdot \sum_{1}^{n} T M P_{i}^{2}-\left(\sum_{1}^{n} T M P_{i}\right)^{2}}
\end{aligned}
$$

In addition, a modified flux-step method based on the method proposed by van der Marel et al. [25] was carried out in order to determinate the $\mathrm{J}_{\mathrm{C}}$ of each operating interval. Each $\mathrm{J}_{\mathrm{C}}$ was calculated according to the weak definition of this concept $\left(\mathrm{J}_{\mathrm{CW}}\right)$, i.e. the flux above which the relationship between J and TMP becomes non-linear. When applying this method, the duration of both filtration and relaxation stages was set to $15 \mathrm{~min}$. The step size was arbitrarily set to $1.22 \mathrm{LMH}$ of $\mathrm{J}_{20}$ (equivalent to a permeate 
flow-rate of $50 \mathrm{~L} \mathrm{~h}^{-1}$ ). The relaxation stages were conducted using the same $\mathrm{SGD}_{\mathrm{m}}$ as in the filtration stages.

\section{Results and discussion}

\subsection{Long-term SAnMBR performance}

\subsubsection{Evolution of the filtering resistance}

Figure 2 shows the average daily $\mathrm{R}_{\mathrm{T}}$ (calculated using Eq. 1) obtained during the operating period, and the average daily MLTS level in the anaerobic sludge entering the membrane tank. It must be said that the MLTS level in the membrane tank increased (up to $5 \mathrm{~g} \mathrm{~L}^{-1}$ ) as per the ratio between the net permeate flow rate and the sludge flow rate entering the membrane tank. As mentioned before, the MLTS variation in the anaerobic sludge was the result of the different HRTs studied by means of the remaining parallel membrane tank (MT2), which was operated according to the biological process.

Figure 2 shows how any variation in the MLTS level affects $R_{T}$. Nevertheless, even at high MLTS levels (up to $25 \mathrm{~g} \mathrm{~L}^{-1}$ ), $\mathrm{R}_{\mathrm{T}}$ remained at adequate values (below $3 \cdot 10^{12} \mathrm{~m}^{-}$ ${ }^{1}$ ). Above this value a sudden increase in $\mathrm{R}_{\mathrm{T}}$ was observed. This behaviour can be explained by the following: 1 ) the low TMP (below 0.1 bars) achieved throughout the experimental period minimised membrane compression and gave a stable $\mathrm{R}_{\mathrm{M}}$ value; 2 ) $\mathrm{R}_{\mathrm{T}}$ dropped back to previous values when MLTS level fell, thereby indicating that no significant irreversible fouling component (related to $\mathrm{R}_{\mathrm{I}}$ ) contributed to $\mathrm{R}_{\mathrm{T}}$; and 3) when the critical filtration conditions were exceeded (on days 135 to 170, and on days 190 to 220), a sharp increase on $R_{T}$ was observed due to a higher cake layer formation rate (i.e. 
the accumulation of more reversible fouling on the membrane surface). It must be said that $\mathrm{R}_{\mathrm{C}}$ is caused by two different effects: the cake layer formation rate (due to the filtration process) and the cake layer removal rate (due mainly to biogas sparging). It is a well-known fact that at an established $\mathrm{SGD}_{\mathrm{m}}$ the cake layer removal efficiency decreases as the MLTS level increases. As can be concluded from this figure, on days 135 to 170 and days 190 to 220 , the $\mathrm{SGD}_{\mathrm{m}}$ applied to the membrane tank was not enough to meet the membrane requirements necessary to maintain sub-critical filtration conditions because of the high MLTS levels reached.

Hence, according to our study, where $\mathrm{R}_{\mathrm{I}}$ component was observed to be negligible, the component making the main contribution to $\mathrm{R}_{\mathrm{T}}$ was $\mathrm{R}_{\mathrm{C}}$ (between $8 \cdot 10^{11}$ and $16 \cdot 10^{11}$ $\mathrm{m}^{-1}$, approx. $60-75 \% \mathrm{R}_{\mathrm{C}} / \mathrm{R}_{\mathrm{T}}$, calculated as the difference between $\mathrm{R}_{\mathrm{T}}$ and $\mathrm{R}_{\mathrm{M}}$ ), whilst a constant contribution of about $5 \cdot 10^{11} \mathrm{~m}^{-1}$ (calculated from the original $\mathrm{K}_{20}$ treating clean water in similar operating conditions: approx. $650 \mathrm{LMH}$ bar $\left.^{-1}\right)$ was attributed to $\mathrm{R}_{\mathrm{M}}(25$ - $40 \% \mathrm{R}_{\mathrm{M}} / \mathrm{R}_{\mathrm{T}}$ ). It must be emphasised that the $\mathrm{R}_{\mathrm{T}}$ values obtained in this work were considerably lower than the results given in other studies on submerged MBR systems. For instance, Botino et al. [26] determined by means of the flux-step method $\mathrm{R}_{\mathrm{T}}$ values from $1.56 \cdot 10^{12}$ to $4.82 \cdot 10^{12} \mathrm{~m}^{-1}$ for aerobic sub-critical filtration (MLTS levels from 3 to $14 \mathrm{~g} \mathrm{~L}^{-1}$ and $\mathrm{J}_{\mathrm{C}}$ values from 4.9 to $14.7 \mathrm{LMH}$ ); Lin et al., [5] obtained $\mathrm{R}_{\mathrm{T}}$ values of $8.47 \cdot 10^{13}$ and $1.72 \cdot 10^{13} \mathrm{~m}^{-1}$ at fluxes around 2.4 and $7.2 \mathrm{LMH}$ treating kraft evaporator condensate under thermophilic and mesophilic temperature conditions, respectively; and Martinez-Sosa et al. $[13,14]$ observed $\mathrm{R}_{\mathrm{T}}$ values from approx. $4.0 \cdot 10^{12}$ to $1.4 \cdot 10^{13} \mathrm{~m}^{-1}$ treating urban wastewater at $7 \mathrm{LMH}$ of $\mathrm{J}_{20}$ and TSS (from approx. 9.5 to $20 \mathrm{~g} \mathrm{~L}^{-1}$ ). Nevertheless, no stable operation of membranes was possible at $\mathbf{J}_{20}$ over $10 \mathrm{LMH}$.

The low $\mathrm{R}_{\mathrm{T}}$ values obtained in our study can be attributed to the low cake layer 
formation throughout the operating period (the average TMP was around 0.1 bars), resulting in a low $R_{C}$ contribution to $R_{T}$. Hence, the contribution of $R_{M}$ to $R_{T}$ became significant as a result of the low $\mathrm{R}_{\mathrm{C}}$ achieved. It must be emphasised that the membranes were operated sub-critically during almost the whole operating period. Only when the critical filtration conditions were exceeded (on days 135 to 170, and days 190 to 220) did $R_{C}$ became the only major contribution to $R_{T}$, reaching values of around $5.5 \cdot 10^{12} \mathrm{~m}^{-}$

${ }^{1}$ (i.e. about $90 \% \mathrm{R}_{\mathrm{C}} / \mathrm{R}_{\mathrm{T}}$ ). Even in supra-critical filtration conditions $\mathrm{R}_{\mathrm{T}}$ remained under $1 \cdot 10^{13} \mathrm{~m}^{-1}$. Since low $\mathrm{R}_{\mathrm{T}}$ values directly mean low energy consumptions related to permeation, the results shown in Figure 2 highlight the necessity of optimising the physical separation process in SAnMBR systems in order to maximise the economic feasibility of this technology.

\subsubsection{Evolution of the fouling rate}

Figure 3 shows the fouling rate profile (calculated with Eq. 3) obtained during the operating period, as well as the MLTS level in the anaerobic sludge fed to the membrane tank. The fouling rate and MLTS level are both daily averages. As can be observed in Figure 3, the fouling rate remained at low values (below $10 \mathrm{mbar} \mathrm{min}^{-1}$ ) until the MLTS raised the above-mentioned threshold concentration (around $25 \mathrm{~g} \mathrm{~L}^{-1}$ ). Above this value, the fouling rate showed a sharp increase due to exceeding the critical filtration conditions. In fact, the fouling rate reached unsustainable values (around 100 mbar $\min ^{-1}$ ) at quite large MLTS levels (around $30 \mathrm{~g} \mathrm{~L}^{-1}$ ). For instance, at an $\mathrm{SGD}_{\mathrm{m}}$ of $0.23 \mathrm{Nm}^{3} \mathrm{~h}^{-1} \mathrm{~m}^{-2}$ and a MLTS level of 28 and $23 \mathrm{~g} \mathrm{~L}^{-1}$, the $20^{\circ} \mathrm{C}$-normalised $\mathrm{J}_{\mathrm{CW}}$ $\left(\mathrm{J}_{\mathrm{CW}, 20}\right)$ calculated by the flux-step method resulted in approx. 10 and $13 \mathrm{LMH}$, respectively (see Figure 4). It must be emphasised that since the flux-step method was conducted using industrial scale membranes, the differences between the theoretical and 
the observed values were reduced [22]. The fouling rate profile in Figure 3 shows that the filtration process remained sub-critical until day 135 . As mentioned before, in the periods from days 135 to 170 (period ii) and days 190 to 220 (period iii), supra-critical filtration conditions were reached, as shown by the significant fouling rate obtained, due to the high MLTS levels reached. Nevertheless, it was possible to operate the membranes at low fouling rates (below $20 \mathrm{mbar}^{\mathrm{min}}{ }^{-1}$ ) even when operating at high MLTS levels (up to $25 \mathrm{~g} \mathrm{~L}^{-1}$ ) without applying unsustainable $\mathrm{SGD}_{\mathrm{m}}$ values $\left(\mathrm{SGD}_{\mathrm{m}}\right.$ was always under $0.25 \mathrm{Nm}^{3} \mathrm{~h}^{-1} \mathrm{~m}^{-2}$ ). Finally, from days 210 to 315 (period iv) the fouling rate decreased because of the decrease in the MLTS level.

The results shown in figures 2 and 3 highlight the possibility of operating membranes anaerobically at higher MLTS levels (up to $25 \mathrm{~g} \mathrm{~L}^{-1}$ ) than aerobically, since no oxygen for organic matter removal is required. MLTS levels in aerobic MBRs are limited due to oxygen transfer limitation problems [27]. In this respect, the operating volume envisaged originally can be reduced considerably in comparison with the volume required under aerobic conditions. Moreover, these results confirm that the MLTS level is a key factor governing membrane fouling in this HF-SAnMBR system, since membrane permeability was restored to previous values when the MLTS level fell. Nevertheless, the effect of other factors mainly related to sludge characteristics (i.e. biomass, SMP and EPS concentrations) on membrane fouling should be considered.

\subsection{Sub-critical filtration conditions}

Figure 4 shows $J_{C W, 20}$ to be directly related to $\mathrm{SGD}_{\mathrm{m}}$ when operating at high MLTS levels (at 23 and $28 \mathrm{~g} \mathrm{~L}^{-1}$ ). This relationship predicts that it is theoretically possible to operate membranes sub-critically at high MLTS levels without applying prohibitive 
$\mathrm{SGD}_{\mathrm{m}}$ levels (from 0.17 to $0.50 \mathrm{Nm}^{3} \mathrm{~h}^{-1} \mathrm{~m}^{-2}$ ) when working at $\mathrm{J}_{20}$ between 10 and 15 LMH. For instance, as Figure 4 shows, it is theoretically possible to operate membranes sub-critically at a $\mathrm{J}_{20}$ of $14 \mathrm{LMH}$ by applying an $\mathrm{SGD}_{\mathrm{m}}$ of approx. $0.25 \mathrm{Nm}^{3} \mathrm{~h}^{-1} \mathrm{~m}^{-2}$ at $23 \mathrm{~g} \mathrm{~L}^{-1}$ of MLTS, whilst SGD $\mathrm{m}$ has to be set to $0.50 \mathrm{Nm}^{3} \mathrm{~h}^{-1} \mathrm{~m}^{-2}$ for MLTS levels of around $28 \mathrm{~g} \mathrm{~L}^{-1}$. On the other hand, when operating at constant $\mathrm{SGD}_{\mathrm{m}}$ a decline in $\mathrm{J}_{\mathrm{CW}, 20}$ of up to $4 \mathrm{LMH}$ could be reached when MLTS increases from 23 to $28 \mathrm{~g} \mathrm{~L}^{-1}$. Therefore, MLTS levels above $28 \mathrm{~g} \mathrm{~L}^{-1}$ are not advisable because this would cause $\mathrm{J}_{\mathrm{CW}, 20}$ values to drop below $10 \mathrm{LMH}$ (for $\mathrm{SGD}_{\mathrm{m}}$ of $0.23 \mathrm{Nm}^{3} \mathrm{~h}^{-1} \mathrm{~m}^{-2}$ ) and would make the filtration process unnecessarily expensive when operating sub-critically.

Important to note is the competitive $\mathrm{J}_{\mathrm{CW}, 20}$ values obtained in our study (taking into account the operating solids concentration) in comparison with other $\mathrm{J}_{\mathrm{C}}$ values found in recent MBR literature. Botino et al. [26] obtained $\mathrm{J}_{\mathrm{C}}$ values from 4.9 to 14.7 LMH in an aerobic HF-MBR at TSS levels from 3 to $14 \mathrm{~g} \mathrm{~L}^{-1}$; Monclus et al. [28] identified $\mathrm{J}_{\mathrm{C}}$ of 14.5 LMH in an aerobic HF-MBR operated at TSS of $8 \mathrm{~g} \mathrm{~L}^{-1}$ and $\mathrm{SGD}_{\mathrm{m}}$ of $0.24 \mathrm{Nm}^{3} \mathrm{~h}^{-1} \mathrm{~m}^{-2}$; Martin-Garcia et al. [29] obtained $\mathrm{J}_{\mathrm{C}}$ values from approx. 2 to 5 LMH in a HF-SAnMBR operated at TSS of $7.7 \mathrm{~g} \mathrm{~L}^{-1}$ and $\mathrm{SGD}_{\mathrm{m}}$ from 0.19 to $1.16 \mathrm{Nm}^{3}$ $\mathrm{h}^{-1} \mathrm{~m}^{-2}$, whilst the same authors obtained $\mathrm{J}_{\mathrm{C}}$ values from approx. 3 to $14 \mathrm{LMH}$ in aerobic HF-MBR operated at TSS of $8.7 \mathrm{~g} \mathrm{~L}^{-1}$ and $\mathrm{SGD}_{\mathrm{m}}$ from 0.19 to $1.16 \mathrm{Nm}^{3} \mathrm{~h}^{-1} \mathrm{~m}^{-2}$; and Tiranuntakul et al. [30] reported $\mathrm{J}_{\mathrm{C}}$ values from 9 to $16 \mathrm{LMH}$ calculated by different methods in an aerobic MBR operated at TSS around 6- $7 \mathrm{~g} \mathrm{~L}^{-1}$ and $\mathrm{SGD}_{\mathrm{m}}$ of $0.36 \mathrm{Nm}^{3}$ $\mathrm{h}^{-1} \mathrm{~m}^{-2}$. The results obtained in our study predict that it is theoretically possible to maintain sub-critical filtration conditions meanwhile operating at sustainable $\mathbf{J}_{20}$ values when operating membranes at quite high MLTS levels (up to around $25 \mathrm{~g} \mathrm{~L}^{-1}$ ), without applying a prohibitive $\mathrm{SGD}_{\mathrm{m}}$. As mentioned before, these results confirm that the optimisation of the physical separation process in every operating range will result in 
significant energy savings in HF-SAnMBR systems.

\subsection{Membrane operating mode}

Figure 5a shows the TMP profile at the end of the second experimental period (day 135 ) and also the membrane operating mode. In this case, the MLTS in the anaerobic reactor was $22 \mathrm{~g} \mathrm{~L}^{-1}$, whilst the MLTS in the membrane tank was estimated to be approximately $24.5 \mathrm{~g} \mathrm{~L}^{-1}$ according to the ratio between the net permeate flow rate and the sludge flow rate entering the membrane tank. As stated before, the critical flux (normalised at $20^{\circ} \mathrm{C}$ ) under these conditions was calculated to be approximately 13 LMH. Hence, the membranes were operated at sub-critical filtration conditions. Figure 5a shows the total TMP recovery after the relaxation stage, which confirms that no irreversible fouling was detected throughout the operating period. The maximum TMP was 0.08 bars, which is very low compared to both the maximum value recommended by the supplier ( 0.6 bars) and the normal values in aerobic membrane bioreactors (approximately 0.1 to 0.3 bars).

Figure $5 \mathrm{~b}$ enlarges a 45 -minute operating period taken from Figure 5a, as well as a 45-minute operating period taken from days 195 and 250 (third and fourth experimental period, respectively). The MLTS in the anaerobic reactor was $25 \mathrm{~g} \mathrm{~L}^{-1}$ on day 195 and $22 \mathrm{~g} \mathrm{~L}^{-1}$ on day 250, whilst the MLTS in the membrane tank was estimated to be approximately 28.5 and $25.5 \mathrm{~g} \mathrm{~L}^{-1}$, respectively. The maximum TMP on days 195 and 250 was 0.15 and 0.11 bars, respectively. Figure $5 \mathrm{~b}$ shows that the TMP remained practically constant during the filtration periods at $10 \mathrm{LMH}$ of $\mathrm{J}_{20}$ and MLTS of $22 \mathrm{~g} \mathrm{~L}^{-1}$ (day 135). On the other hand, a slight increase in TMP was observed when membranes were operated at $12 \mathrm{LMH}$ of $\mathrm{J}_{20}$ and MLTS of $25 \mathrm{~g} \mathrm{~L}^{-1}$ (day 195), and at $13.3 \mathrm{LMH}$ of 
$\mathbf{J}_{20}$ and MLTS of $22 \mathrm{~g} \mathrm{~L}^{-1}$ (day 250). The higher fouling rate values observed on days 195 and 250 indicated that membranes were operated critically. Nevertheless, continuous increase on TMP through consecutive filtration stages was observed neither on day 195 nor on day 250. Moreover, as stated before, the total filtration resistance observed in this study was mainly related to the reversible fouling component. Therefore, the physical cleaning mechanisms (relaxation, back-flush and shear intensity of gas sparging) were enough to completely remove the physical fouling from the membrane surface. This fouling removal also highlights the importance of establishing both an adequate membrane configuration and an adequate membrane operating mode in order to minimise filtration problems such as clogging and irreversible/irrecoverable fouling.

Hence, proper membrane configuration and operating mode may allow for establishing competitive transmembrane fluxes in order to increase the economic feasibility of full-scale anaerobic MBRs compared to full-scale aerobic MBRs, which commonly operate at $\mathbf{J}_{20}$ from 10 to $25 \mathrm{LMH}$ [31]. In our work, membranes were operated at gross $\mathbf{J}_{20}$ values from 10 to $13.3 \mathrm{LMH}$, resulting in low fouling rate values. Recent literature on anaerobic MBRs has also shown the potential of SAnMBR technology for urban wastewater treatment. For instance, Martinez-Sosa et al. [32] achieved proper long-term operation of membranes (resulting in low fouling rates) at $\mathbf{J}$ values of up to $10 \mathrm{LMH}$ and TSS levels of up to $15 \mathrm{~g} \mathrm{~L}^{-1}$. However, above these $\mathrm{J}$ values a considerable increase in fouling rate was observed since the critical flux was established at 7 LMH for similar TSS. In contrast, our study showed lower TMP and fouling rates at higher $\mathbf{J}_{20}$ than the above-mentioned study, whilst operating at similar gas sparging intensities. This behaviour can be mainly attributed to the membrane scale. Membrane length is a key design parameter that not only affects the shear conditions 
and gas sparging efficiency, but also the grade of lateral movement, which also contributes to partially-removing the cake layer. Moreover, the transmembrane fluxes used in our work are higher than the fluxes applied in SAnMBR systems treating industrial wastewater, which are commonly operated at transmembrane fluxes below 10 LMH whilst operating at TSS levels around $10 \mathrm{~g} \mathrm{~L}^{-1}$ [33]. Hence, the results presented in our work highlight the potential of SAnMBR technology for urban wastewater treatment at full-scale.

\subsection{Chemical factors minimising the onset of irreversible fouling problems}

Apart from operating at sub-critical filtration conditions and establishing an adequate membrane operating mode, other factors were identified as key parameters minimising possible irreversible/irrecoverable fouling problems in this HF-SAnMBR system, such as the relatively low operating $\mathrm{pH}$ (around 6.7), which reduces the chemical precipitation propensity.

Throughout the operating period shown in Figure 2 and 3, the $\mathrm{pH}$ of the mixed liquor remained relatively stable around 6.7. This behaviour highlights the importance in SAnMBR systems of carrying out membrane scouring with a fraction of the produced biogas. In these systems it is possible to assume that equilibrium conditions between liquid and gas phases are achieved, i.e. the effluent $\mathrm{CO}_{2}$ concentration will be similar to the $\mathrm{CO}_{2}$ solubility concentration. Thus, most of the $\mathrm{CO}_{2}$ produced remained in the mixed liquor working as a $\mathrm{pH}$ tampon factor. This can be confirmed by the high Alk

values of the mixed liquor (around $600 \mathrm{mgCaCO}_{3} \mathrm{~L}^{-1}$ during the operating period), in comparison with the influent Alk (around $310 \mathrm{mgCaCO}_{3} \mathrm{~L}^{-1}$ ). It is important to highlight that chemical precipitates, which are usually produced at $\mathrm{pH}$ values greater 
than 7 , increase the irreversible fouling propensity due to increasing both superficial and internal fouling. Since the $\mathrm{pH}$ was mainly under 7 , the possible fouling problems related to chemical precipitation were reduced.

The equilibrium speciation programme MINTEQA2 [34] was used to estimate the expected concentrations for the biologically induced precipitates most likely in this SAnMBR system: amorphous calcium phosphate one, two, and $\beta$ (ACP 1, ACP 2 and ACP $\beta$, respectively), hydroxyapatite (HAP), struvite (MAP) and calcite. This programme calculates the saturation index (SI) of the selected precipitates, thereby establishing the stability order of precipitation or dissolution. Indeed, if SI is positive the solution is oversaturated and there is possibility of chemical precipitation. On the other hand, if SI is negative the solution is undersaturated and no chemical precipitation is expected. The value of 13.3 - as proposed by Pastor et al. [35] - was selected for the struvite solubility product $\left(p K_{\mathrm{SMAP}}\right)$. Table 1 shows the compound concentrations used for evaluating the chemical precipitation propensities, which were obtained from the average experimental values of the mixed liquor. Table 2 shows the estimated SI values for the selected precipitates calculated at different $\mathrm{pH}$ levels $(6.5,6.75,7$ and 7.25$)$ and temperature $\left(20,25\right.$ and $\left.33^{\circ} \mathrm{C}\right)$.

As Table 2 shows, the results obtained from MINTEQA2 indicated that the induced formation of the selected precipitates is low when working at $\mathrm{pH}$ values of less than 7 , although chemical precipitation propensity increases as $\mathrm{pH}$ increases. For $\mathrm{pH}$ values lower than 6.75 only the SI of HAP was significantly positive as regards its precipitation. However, this precipitate is formed from its precursors (ACP 1, ACP 2 and ACP $\beta$ ) which present SI values lower than or close to zero. It is important to 
highlight that no significant amount of struvite is expected even at $\mathrm{pH}$ values of around 7.5 .

Besides chemical precipitation propensity, recent literature has demonstrated that $\mathrm{pH}$ affects the anaerobic sludge properties thus affecting the biofouling propensity. In this respect, Jane Gao et al. [36] observed that elevated pH shocks induced the dispersion of sludge flocs resulting in sub-products generation (colloids and solutes or biopolymers). On the other hand, Sweity et al. [37] studied how $\mathrm{pH}$ affects on the adherence and fouling propensity of EPS over ultrafiltration (UF) membranes. These authors observed that the fouling rate of UF membranes operated at similar EPS concentrations was significantly lower at $\mathrm{pH}$ value of 6.3 than at $\mathrm{pH}$ value of 8.3.

Therefore, further research is needed in order to assess the actual effect of $\mathrm{pH}$ on membrane fouling.

\section{Conclusions}

The membrane performance demonstrated that HF-SAnMBR is a promising technology for urban wastewater treatment. MLTS was identified as the main factor affecting membrane performance. Nevertheless, $\mathrm{R}_{\mathrm{T}}$ remained at sustainable values even when operating membranes at MLTS levels of approx. $25 \mathrm{~g} \mathrm{~L}^{-1}$. Beneath this level, the fouling rate remained low (less than $20 \mathrm{mbar}^{\mathrm{min}}{ }^{-1}$ ) and suddenly increased when this threshold value was exceeded. After almost one year of operation no irreversible fouling problems (usually related to chemical precipitation in the membranes) were detected, and low fouling rates were observed even when MLTS was high. This was mainly attributed to: operating at sub-critical filtration conditions; establishing an adequate 
membrane operating mode; and working at $\mathrm{pH}$ values of less than 7 as a result of some of the biogas produced being recycled for in-situ sparging

\section{Acknowledgements}

This research work has been supported by the Spanish Research Foundation (CICYT Projects CTM2008-06809-C02-01 and CTM2008-06809-C02-02, and MICINN FPI grant BES-2009-023712) and Generalitat Valenciana (Projects GVAACOMP2010/130 and GVA-ACOMP2011/182), which are gratefully acknowledged.

\section{References}

[1] H.J. Lin, K. Xie, B. Mahendran, D.M. Bagley, K.T. Leung, S.N. Liss, B.Q. Liao, Factors affecting sludge cake formation in a submerged anaerobic membrane bioreactor, J. Membr. Sci. 361 (2010) 126 134.

[2] A.L. Smith, L.B. Stadler, N.G. Love, S.J. Skerlos, L. Raskin, Perspectives on anaerobic membrane bioreactor treatment of domestic wastewater: A critical review, Bioresour. Technol. (2012), http://dx.doi.org/10.1016/j.biortech.2012.04.055.

[3] S. Judd, C. Judd, The MBR Book: Principles and Applications of Membrane Bioreactors for Water and Wastewater Treatment, 2 ${ }^{\text {nd }}$ edition, Elsevier, ISBN: 978-0-08-096682-3, 2011.

[4] I.S. Chang, P.L. Clech, B. Jefferson, S. Judd, Membrane fouling in membrane bioreactors for wastewater treatment, J Environ Eng. 128 (2002) 1018 - 1029.

[5] H.J. Lin, K. Xie, B. Mahendran, D.M. Bagley, K.T. Leung, S.N. Liss, B.Q. Liao, Sludge properties and their effects on membrane fouling in submerged anaerobic membrane bioreactors (SAnMBRs), Water Res. 43 (2009) 3827 - 3837.

[6] N. Martí, A. Bouzas, A. Seco, J. Ferrer, Struvite precipitation assessment in anaerobic digestion processes, Chem. Eng. J. 141 (2008) $67-74$.

[7] B.Q. Liao, J.T. Kraemer, D.M.Bagley, Anaerobic membrane bioreactors: Applications and research 
directions, Crit. Rev. Env. Sci. Tec. 36 (2006) 489 - 530.

[8] M.V.G. Vallero, G. Lettinga, P.N.L. Lens, High rate sulfate reduction in a submerged anaerobic membrane bioreactor (SAMBaR) at high salinity, J Membr Sci. 253 (2005) 217 - 232.

[9] L. Dvořák, M. Gómez, M. Dvořáková, I. Růžičková, J. Wanner, The impact of different operating conditions on membrane fouling and EPS production, Bioresource Technol. 102 (2011) 6870 - 6875.

[10] P. Bachin, P. Aimar, V. Sanchez, Model for colloidal fouling of membranes. AIChE J. 41 (1995) 368 $-377$.

[11] Field R.W., Wu D., Howell J.A., and Gupta B.B. (1995) Critical flux concept for microfiltration fouling, J. Membr. Sci. 100 (3), 259 - 272.

[12] P. Cote, Z. Alam, J. Penny, Hollow fibre membrane life in membrane bioreactors (MBR), Desalination 288 (2012) $145-151$.

[13] D. Martinez-Sosa, B. Helmreich, H. Horn, Anaerobic submerged membrane bioreactor (AnSMBR) treating low-strength wastewater under psychrophilic temperature conditions, Process Biochem. 47 (2012) $792-798$.

[14] D. Martinez-Sosa, B. Helmreich, T. Netter, S. Paris, F. Bischof, H. Horn, Anaerobic submerged membrane bioreactor (AnSMBR) for municipal wastewater treatment under mesophilic and psychrophilic temperature conditions, Bioresour. Technol. 102 (2011) 10377 - 10385.

[15] A. Akram, D.C. Stuckey, Flux and performance improvement in a submerged anaerobic membrane bioreactor (SAMBR) using powdered activated carbon (PAC), Process Biochem. 43 (2008) 93 - 102.

[16] R. Yoo, J. Kim, P.L. McCarty, J. Bae, Anaerobic treatment of municipal wastewater with a staged anaerobicfluidized membrane bioreactor (SAF-MBR) system, . Bioresour. Technol. 120 (2012) 133 139.

[17] A.Y. Hu, D.C. Stuckey, Treatment of Dilute Wastewaters Using a Novel Submerged Anaerobic Membrane Bioreactor, J Environ Eng. 132 (2006) 190 - 198.

[18] F. Fawehinmi, B. Jefferson, C. Tak, F. Rogalla, Submerged Anaerobic Membrane Bioreactors (SAnMBR): Ready for the Big Ball?, Proceedings of the Water Environment Federation, WEFTEC 2007 (2007) $6393-6401$.

[19] D. Jeison, J.B. van Lier, Cake formation and consolidation: Main factors governing the applicable flux in anaerobic submerged membrane bioreactors (AnSMBR) treating acidified wastewaters, Sep. Purif. Technol. 56 (2007) $71-78$.

[20] Z. Huang, S.L. Ong, H.Y. Ng, Feasibility of submerged anaerobic membrane bioreactor (SAMBR) 
for treatment of low-strength wastewater, Water Sci. Technol. 58 (2008) 1925 - 1931.

[21] B. Lew, S. Tarre, M. Beliavski, C. Dosoretz, M. Green, Anaerobic membrane bioreactor (AnMBR) for domestic wastewater treatment, Desalination 243 (2009) 251 - 257.

[22] A. Robles, M.V. Ruano, F. García-Usach, J. Ferrer, Sub-critical filtration conditions of commercial hollow-fibre membranes in a submerged anaerobic MBR (HF-SAnMBR) system: The effect of gas sparging intensity, Bioresour. Technol. 114 (2012) 247-254.

[23] American Public Health Association/American Water Works Association/Water Environmental Federation, Standard methods for the Examination of Water and Wastewater, $21^{\text {st }}$ edition, Washington DC, USA, 2005.

[24] Water Research Commission, University of Cape Town, Simple titration procedures to determine $\mathrm{H} 2 \mathrm{CO} 3 *$ alkalinity and short-chain fatty acids in aqueous solutions containing known concentrations of ammonium, phosphate and sulphide weak acid/bases, Report No. TT 57/92, Pretoria, Republic of South Africa, 1992.

[25] P. van der Marel, A. Zwijnenburg, A. Kemperman, M. Wessling, H. Temmink, W. van der Meer, An improved flux-step method to determine the critical flux and the critical flux for irreversibility in a membrane bioreactor, J. Membr. Sci. 332 (2009) 24 - 29.

[26] A. Bottino, G. Capannelli, A. Comite, R. Mangano, Critical flux in submerged membrane bioreactors for municipal wastewater treatment, Desalination 245 (2009) 748 - 753.

[27] T. Stephenson, S. Judd, B. Jefferson, K. Brindle, Membrane Bioreactors for Wastewater Treatment, IWA publishing, London, UK, 2000.

[28] H. Monclus, S. Zacharias, A. Santos, M. Pidou, S. Judd, Criticality of Flux and Aeration for a Hollow Fiber Membrane Bioreactor, Sep. Sci. Technol. 45 (2010) 956 - 961.

[29] I. Martin-Garcia, V. Monsalvo, M. Pidou, P. Le-Clech, S.J. Judd, E.J. McAdam, B. Jefferson, Impact of membrane configuration on fouling in anaerobic membrane bioreactors, J. Membr. Sci. 382 (2012) $41-49$.

[30] M. Tiranuntakul, P.A. Schneider, V. Jegatheesan, Assessments of critical flux in a pilot-scale membrane bioreactor, Bioresour. Technol. 102 (2011) 5370 - 5374.

[31] T. Zsirai, P. Buzatu, P. Aerts, S. Judd, Efficacy of relaxation, backflushing, chemical cleaning and clogging removal for an immersed hollow fibre membrane bioreactor, Water Res. 46 (2012) 4499 4507.

[32] D. Martinez-Sosa, B. Helmreich, T. Netter, S. Paris, F. Bischof, H. Horn, Pilot-scale anaerobic 
submerged membrane bioreactor (AnSMBR) treating municipal wastewater: the fouling phenomenon and long-term operation, Water Sci. Technol. 64 (2011) 1804 - 1811.

[33] R.K. Dereli, M.E. Ersahin, H. Ozgun, I. Ozturk, D. Jeison, F. van der Zee, J.B. van Lier, Potentials of anaerobic membrane bioreactors to overcome treatment limitations induced by industrial wastewaters, Bioresour. Technol. (2012), http://dx.doi.org/10.1016/j.biortech.2012.05.139.

[34] J.D. Allison, D.S. Brown, K.J. Novo-Gradak, MINTEQA2/PRODEFA2, A Geochemical Assessment Model for Environmental Systems: Version 3.0, EPA/600/3-91/021, USEPA, Washington DC, USA, 1991.

[35] L. Pastor, D. Mangin, R. Barat, A. Seco, A pilot-scale study of struvite precipitation in a stirred tank reactor: Conditions influencing the process, Bioresour. Technol. 99 (2008) $6285-6291$.

[36] W.J. Jane Gao, H.J. Lin, K.T. Leunga, B.Q. Liao, Influence of elevated pH shocks on the performance of a submerged anaerobic membrane bioreactor, Process Biochem. 45 (2010) 1279 - 1287.

[37] A. Sweity, W. Ying, S. Belfer, G. Oron, M. Herzberg, pH effects on the adherence and fouling propensity of extracellular polymeric substances in a membrane bioreactor, J Membr Sci. 378 (2011) $186-193$. 


\section{Figure and table captions}

Table 1. Mean concentrations entered in the MINTEQA2 programme to estimate the chemical precipitation propensity of the system.

Table 2. Estimated SI values for the main chemical precipitates expected in the system at different operating temperatures and $\mathrm{pH}$.

Figure 1. Flow diagram of the demonstration plant. Nomenclature: RF: rotofilter; ET: equalization tank; AnR: anaerobic reactor; MT: membrane tanks; DV: degasification vessel; CIP: clean-in-place; P: pump; and B: blower.

Figure 2. Evolution of $\mathrm{R}_{\mathrm{T}}$ and MLTS during experimental periods: (i) $\mathbf{J}_{20}$ at $13.3 \mathrm{LMH}$ and $33^{\circ} \mathrm{C}$; (ii) $\mathbf{J}_{20}$ at $10 \mathrm{LMH}$ and $33^{\circ} \mathrm{C}$; (iii) $\mathrm{J}_{20}$ at $12 \mathrm{LMH}$ and $25^{\circ} \mathrm{C}$; and (iv) $\mathrm{J}_{20}$ at $13.3 \mathrm{LMH}$ and $20^{\circ} \mathrm{C}$.

Figure 3. Evolution of reversible fouling rate and MLTS during experimental periods: (i) $\mathbf{J}_{20}$ at $13.3 \mathrm{LMH}$ and $33^{\circ} \mathrm{C}$; (ii) $\mathrm{J}_{20}$ at $10 \mathrm{LMH}$ and $33^{\circ} \mathrm{C}$; (iii) $\mathrm{J}_{20}$ at $12 \mathrm{LMH}$ and $25^{\circ} \mathrm{C}$; and (iv) $\mathrm{J}_{20}$ at $13.3 \mathrm{LMH}$ and 20 ${ }^{\circ} \mathrm{C}$.

Figure 4. Effect of $\mathrm{SGD}_{\mathrm{m}}$ on $\mathrm{J}_{\mathrm{CW} 20}$ at MLTS levels of 23 and $28 \mathrm{~g} \mathrm{~L}^{-1}$.

Figure 5. (a) TMP performance on day 135 of operation (period ii, MLTS of $22 \mathrm{~g} \mathrm{~L}^{-1}$ and $\mathrm{J}_{20}$ at $10 \mathrm{LMH}$ ). (b) Detail of 45-minute period of operation on days 135 (period ii, MLTS of $22 \mathrm{~g} \mathrm{~L}^{-1}$ and $\mathrm{J}_{20}$ at $10 \mathrm{LMH}$ ), 195 (period iii, MLTS of $25 \mathrm{~g} \mathrm{~L}^{-1}$ and $\mathrm{J}_{20}$ at $12 \mathrm{LMH}$ ) and 250 (period iv, MLTS of $22 \mathrm{~g} \mathrm{~L}^{-1}$ and $\mathrm{J}_{20}$ at 13.3 LMH). Nomenclature: R: Relaxation; and F: Filtration. 
Table 1. Mean concentrations entered in the MINTEQA2 programme to estimate the chemical precipitation propensity of the system.

\begin{tabular}{lc}
\hline Parameter & $\begin{array}{c}\text { Value } \\
\left(\mathbf{m m o l ~ L}^{-1}\right)\end{array}$ \\
\hline $\mathrm{NO}_{2}{ }^{-}$ & 0.0398 \\
$\mathrm{NO}_{3}{ }^{-}$ & 0.0418 \\
$\mathrm{NH}_{4}{ }^{+}$ & 3.1000 \\
$\mathrm{PO}_{4}{ }^{3-}$ & 0.1711 \\
$\mathrm{SO}_{4}{ }^{2-}$ & 0.0938 \\
$\mathrm{HS}^{-}$ & 2.9844 \\
$\mathrm{Cl}^{-}$ & 4.5275 \\
$\mathrm{Mg}^{2+}$ & 2.1564 \\
$\mathrm{Ca}^{2+}$ & 4.9150 \\
$\mathrm{~K}^{+}$ & 0.5578 \\
$\mathrm{Na}^{+}$ & 8.6336 \\
$\mathrm{CO}_{3}{ }^{2-}$ & 6.1651 \\
\hline
\end{tabular}


Table 2. Estimated SI values for the main chemical precipitates expected in the system at different operating temperatures and $\mathrm{pH}$.

\begin{tabular}{cccccccc}
\hline $\mathbf{p H}$ & $\mathbf{T}$ & ACP 1 & ACP 2 & ACP $\boldsymbol{\beta}$ & HAP & MAP & Calcite \\
\hline \multirow{3}{*}{6.50} & 20 & -3.998 & -1.227 & -0.136 & 5.698 & -2.217 & -0.063 \\
& 25 & -3.646 & -0.896 & -0.226 & 5.804 & -2.193 & 0.001 \\
& 33 & -3.107 & -0.389 & 0.365 & 5.963 & -2.159 & 0.100 \\
\hline \multirow{2}{*}{6.75} & 20 & -3.215 & -0.444 & 0.647 & 7.124 & -1.827 & 0.172 \\
& 25 & -2.869 & -0.119 & 0.551 & 7.219 & -1.806 & 0.235 \\
& 33 & -2.341 & 0.377 & 0.401 & 7.362 & -1.777 & 0.332 \\
\hline \multirow{2}{*}{7.00} & 20 & -2.504 & 0.267 & 1.358 & 8.440 & -1.472 & 0.404 \\
& 25 & -2.165 & 0.585 & 1.255 & 8.526 & -1.455 & 0.466 \\
& 33 & -1.648 & 1.070 & 1.095 & 8.652 & -1.432 & 0.562 \\
\hline \multirow{2}{*}{7.25} & 20 & -1.861 & 0.910 & 2.001 & 9.654 & -1.152 & 0.634 \\
& 25 & -1.528 & 1.222 & 1.892 & 9.730 & -1.138 & 0.696 \\
& 33 & -1.022 & 1.696 & 1.721 & 9.841 & -1.121 & 0.792 \\
\hline
\end{tabular}




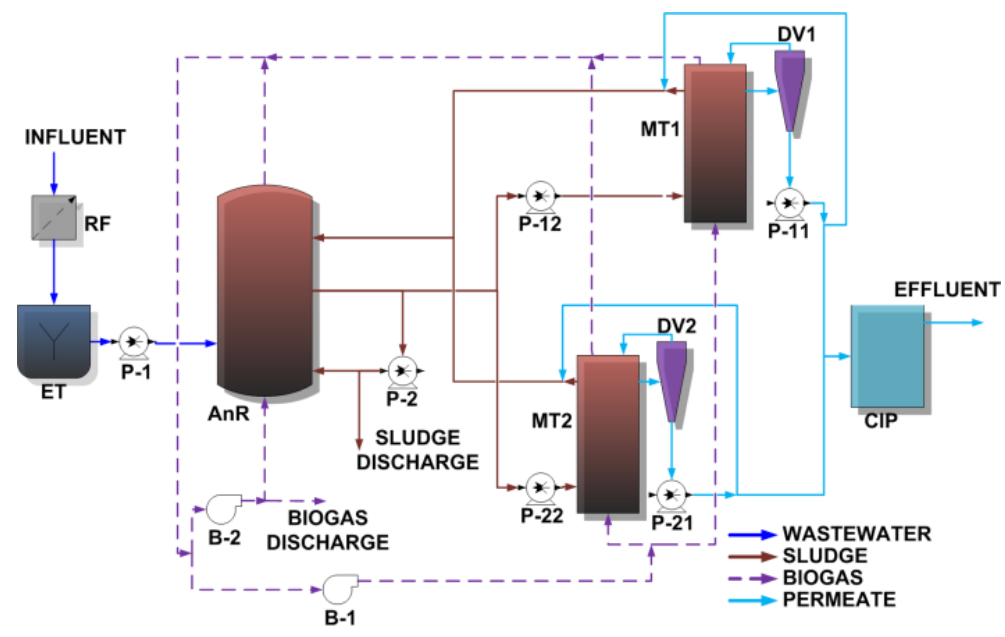

Figure 1. Flow diagram of the demonstration plant. Nomenclature: RF: rotofilter; ET: equalization tank; AnR: anaerobic reactor; MT: membrane tanks; DV: degasification vessel; CIP: clean-in-place; P: pump; and $\mathbf{B}$ : blower. 


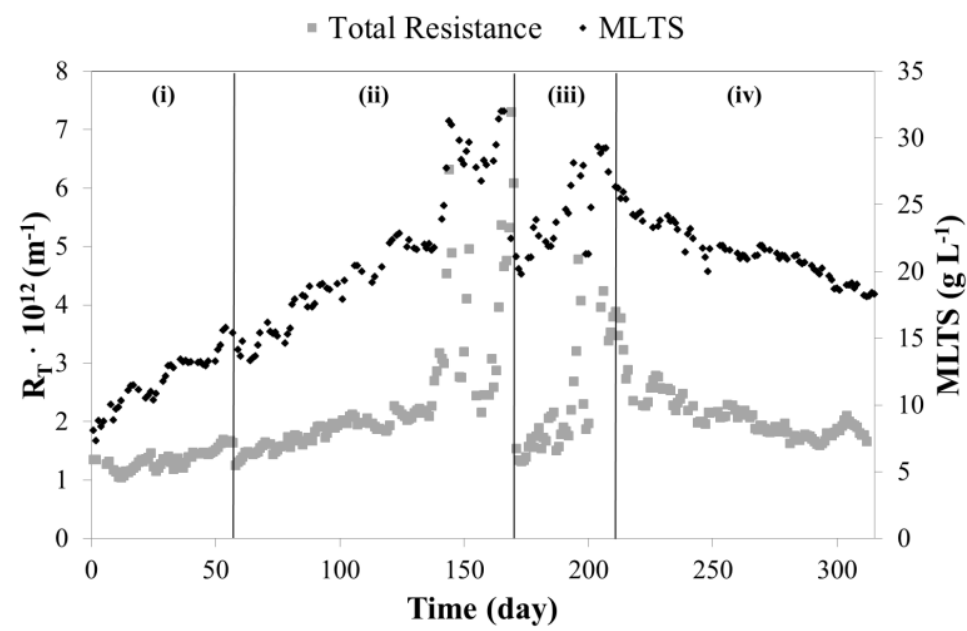

Figure 2. Evolution of $\mathrm{R}_{\mathrm{T}}$ and MLTS during experimental periods: (i) $\mathrm{J}_{20}$ at $13.3 \mathrm{LMH}$ and $33^{\circ} \mathrm{C}$; (ii) $\mathrm{J}_{20}$ at $10 \mathrm{LMH}$ and $33^{\circ} \mathrm{C}$; (iii) $\mathrm{J}_{20}$ at $12 \mathrm{LMH}$ and $25^{\circ} \mathrm{C}$; and (iv) $\mathrm{J}_{20}$ at $13.3 \mathrm{LMH}$ and $20^{\circ} \mathrm{C}$. 


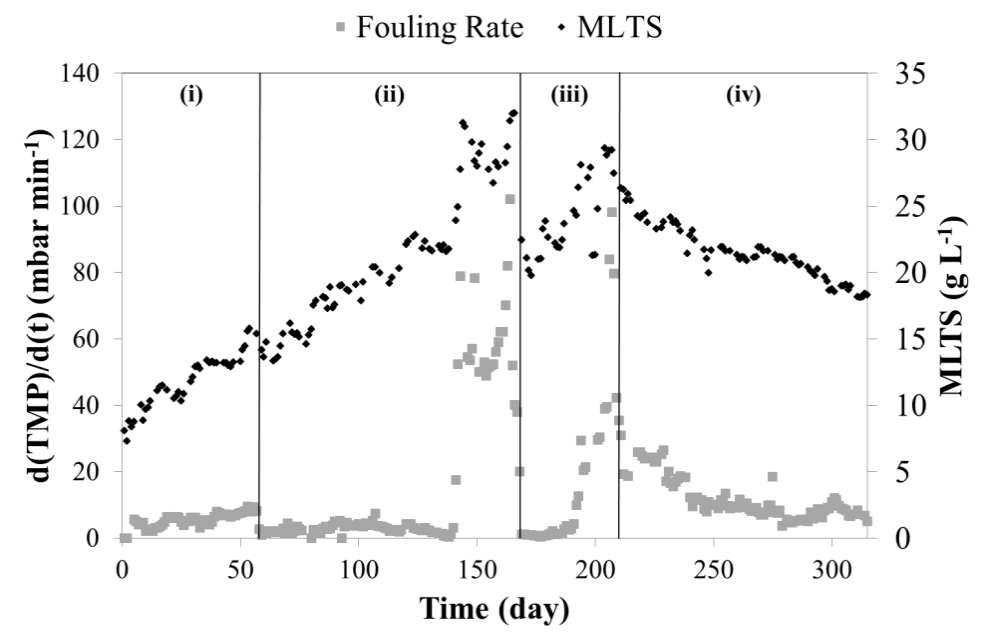

Figure 3. Evolution of reversible fouling rate and MLTS during experimental periods: (i) $\mathrm{J}_{20}$ at $13.3 \mathrm{LMH}$ and $33^{\circ} \mathrm{C}$; (ii) $\mathrm{J}_{20}$ at $10 \mathrm{LMH}$ and $33^{\circ} \mathrm{C}$; (iii) $\mathrm{J}_{20}$ at $12 \mathrm{LMH}$ and $25^{\circ} \mathrm{C}$; and (iv) $\mathrm{J}_{20}$ at $13.3 \mathrm{LMH}$ and 20 ${ }^{\circ} \mathrm{C}$. 


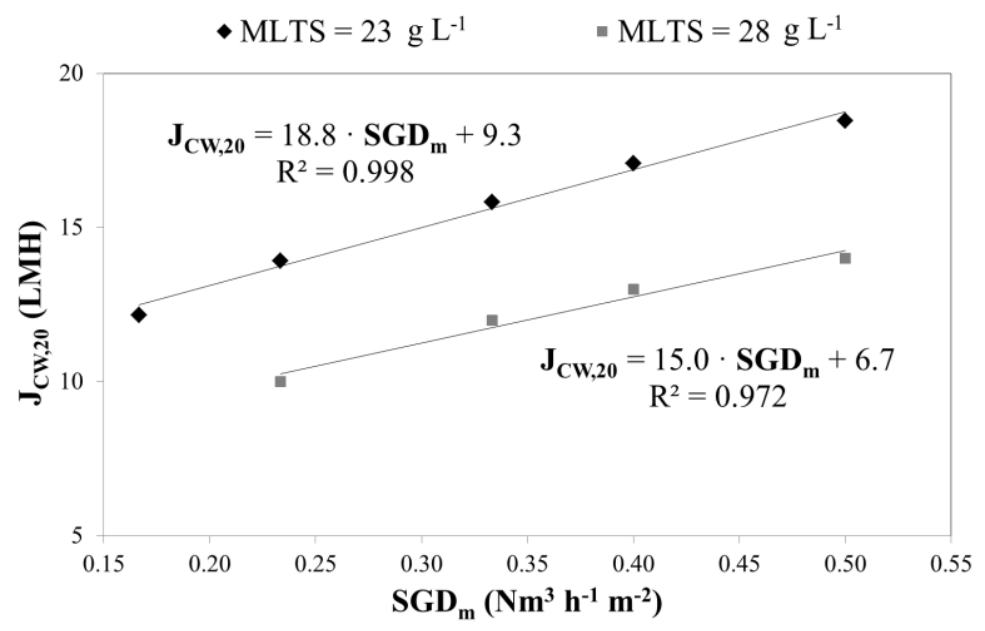

Figure 4. Effect of $\mathrm{SGD}_{\mathrm{m}}$ on $\mathrm{J}_{\mathrm{CW} 20}$ at MLTS levels of 23 and $28 \mathrm{~g} \mathrm{~L}^{-1}$. 


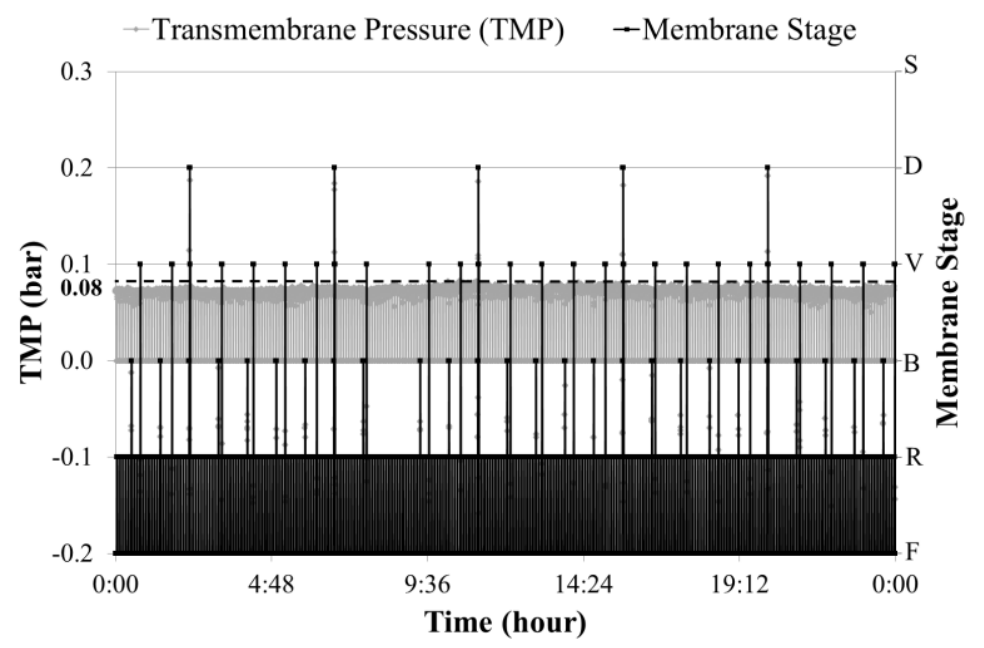

(a)

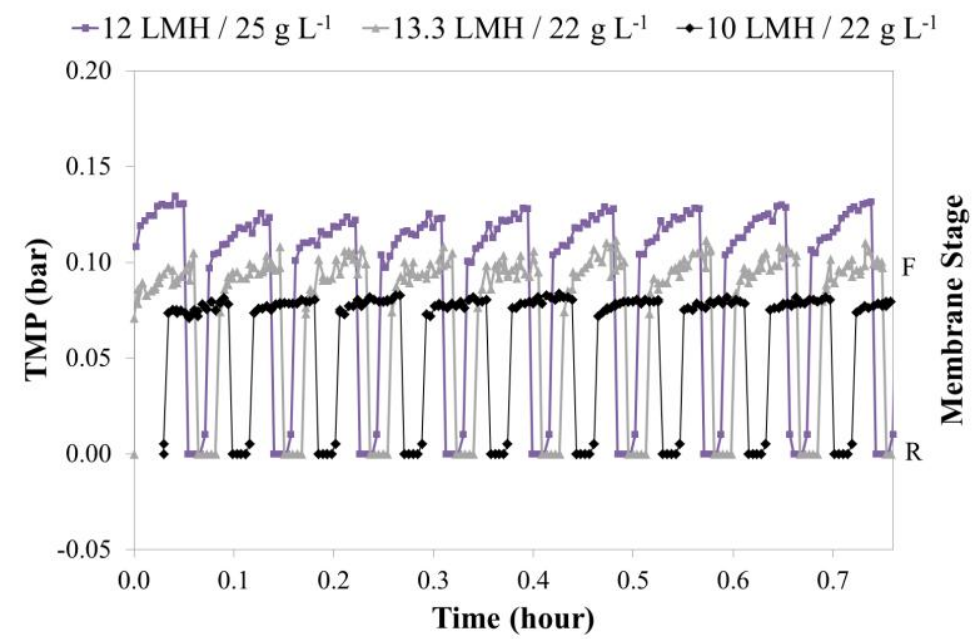

(b)

Figure 5. (a) TMP performance on day 135 of operation (period ii, MLTS of $22 \mathrm{~g} \mathrm{~L}^{-1}$ and $\mathrm{J}_{20}$ at $10 \mathrm{LMH}$ ). (b) Detail of 45-minute period of operation on days 135 (period ii, MLTS of $22 \mathrm{~g} \mathrm{~L}^{-1}$ and $\mathrm{J}_{20}$ at $10 \mathrm{LMH}$ ), 195 (period iii, MLTS of $25 \mathrm{~g} \mathrm{~L}^{-1}$ and $\mathrm{J}_{20}$ at $12 \mathrm{LMH}$ ) and 250 (period iv, MLTS of $22 \mathrm{~g} \mathrm{~L}^{-1}$ and $\mathrm{J}_{20}$ at 13.3 LMH). Nomenclature: R: Relaxation; and F: Filtration. 